\title{
DOCUMENTATION OF STRUCTURAL DAMAGE AND MATERIAL DECAY PHENOMENA IN H-BIM SYSTEMS
}

\author{
Emanuela Lanzara $^{1,2}$, Simona Scandurra ${ }^{1}$, Christian Musella $^{2}$, Daniela Palomba $^{1}$, Antonella di Luggo ${ }^{1}$, Domenico Asprone $^{2}$ \\ ${ }^{1}$ Department of Architecture, University Federico II of Naples \\ ${ }^{2}$ Department of Structures for Engineering and Architecture, University Federico II of Naples
}

KEY WORDS: HBIM, damage modelling, decay, structural damage, HBIM Toolbar, web-based platform

\begin{abstract}
:
The paper presents the results of an experimental research activity aimed to individuate digital tools for an intelligent mapping of structural and material decay of historical buildings.

The activities carried out are part of the context of Scan-to-BIM processes, as they establish a workflow that, starting from 3D survey data, leads to an information model enriched by information related to the conservation state of surfaces and to the structural characteristics of the real building. The experimentation has been performed with the support of a software house, looking forward to turning this workflow into an actual implementation on a BIM software. In this regard, this research becomes part of the context of the studies concerned in the digital management processes of the historical built heritage, setting and testing specific parametrical objects that add to H-BIM models the possibility of documenting and sharing graphical, numerical and descriptive data of decay phenomena and, through integrative information sheets, damage phenomena.
\end{abstract}

\section{INTRODUCTION}

This research project is an offspring of the collaboration between the Department of Architecture and the Department of Structures for Engineering and Architecture of the University Federico II of Naples, and the software house ACCA, aimed to the conversion of specific characteristics of the existing architectonical heritage into BIM systems.

Starting from a review of the state of the art, an experimentation aimed to the implementation of the data related to damage and decay phenomena on the web-based platform usBIMplatform and on the BIM software Edificius, has been carried out.

As it is well-known, transposing these data in information models turns out to be quite burdensome, as it requires long modeling processes, whose results often lack the necessary parametrization to allow a comparative reading or a rapid query.

So, in the context of this research a workflow for the conversion of these data has been defined, in order to realize more streamline procedures. Hence, specific tools have been designed to be inserted in a Heritage BIM toolbar, purposely prepared for the Edificius software.

In addition to that, a part of the data has been organized in specific filings, to be managed through the collaborative webbased platform usBIMplatform, in order to ease its consultation and sharing.

On the operational side, the innovative character of the experimentation has consisted in the creation of modeling tools that added up to the existing ones, improving the application possibilities of BIM processes for the documentation of architectonical historical heritage.

These tools, in fact, allow to add data concerning decay and crack patterns to the geometric model of a building, considering, on one hand, the need for a visual inspection of the investigated phenomenon and, on the other hand, the urge to shorten times of digital reproduction.

Moreover, coherently with the requirements of a BIM model, the informative aspect of each of the smart objects that make up the model has been taken into account, setting specific functions for the input of textual and numerical data, and for their management and sharing.

The implementation of these tools into the software Edificius has allowed to avoid the creation of non-integrable objects - that is, obtained by editing BIM objects that exist in the software library but ideated for different needs - requiring an adaptation to the specific characteristics of the information that has to be expressed.

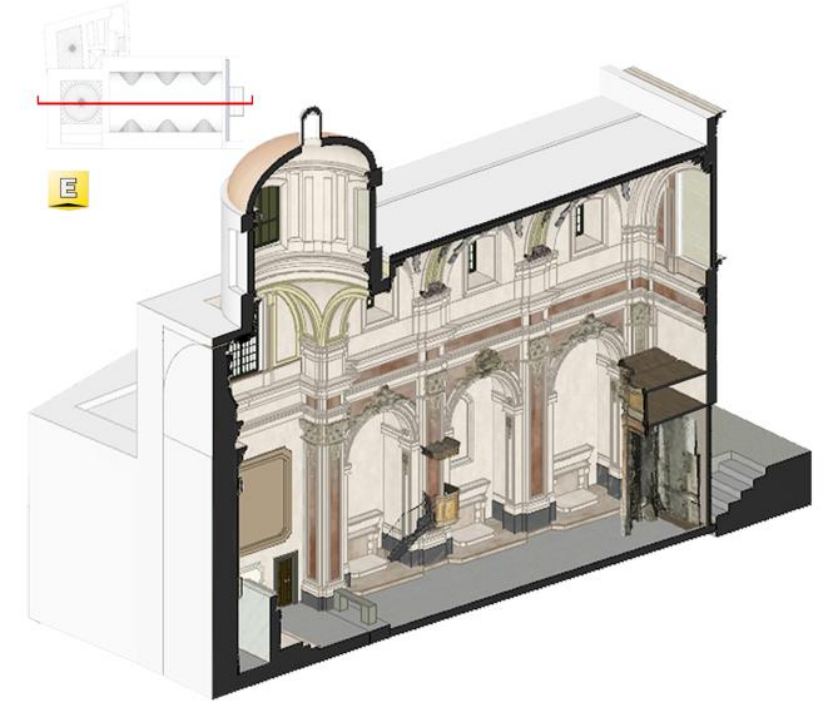

Figure 1. Church of San Pietro in Vinculis, Naples (Italy): BIM model in Edificius. 


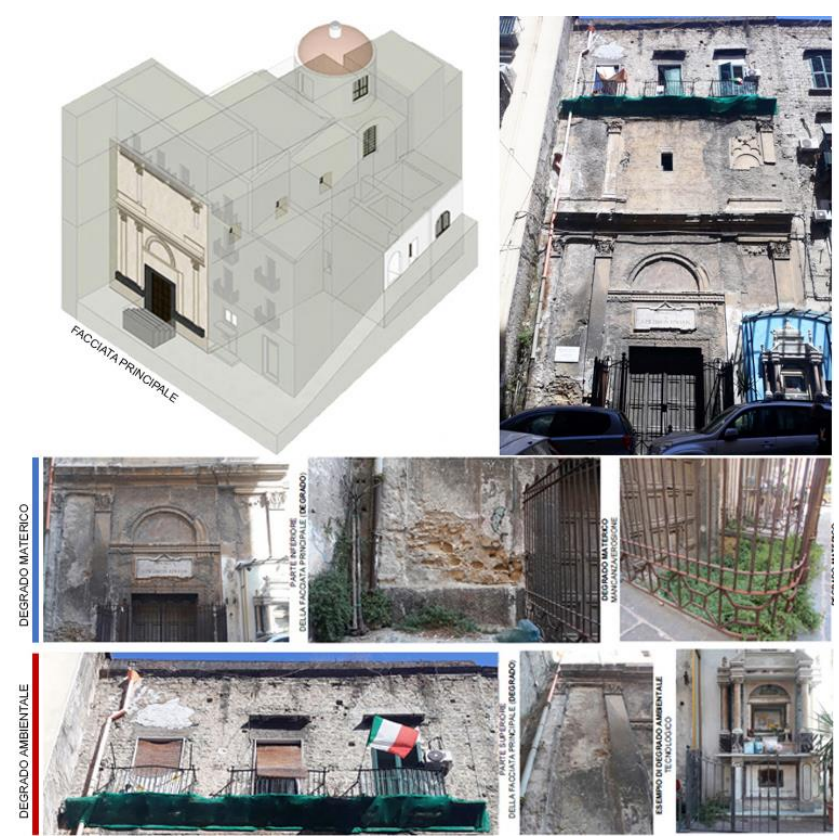

Figure 2. Facade of Church of San Pietro in Vinculis, state of conservation.

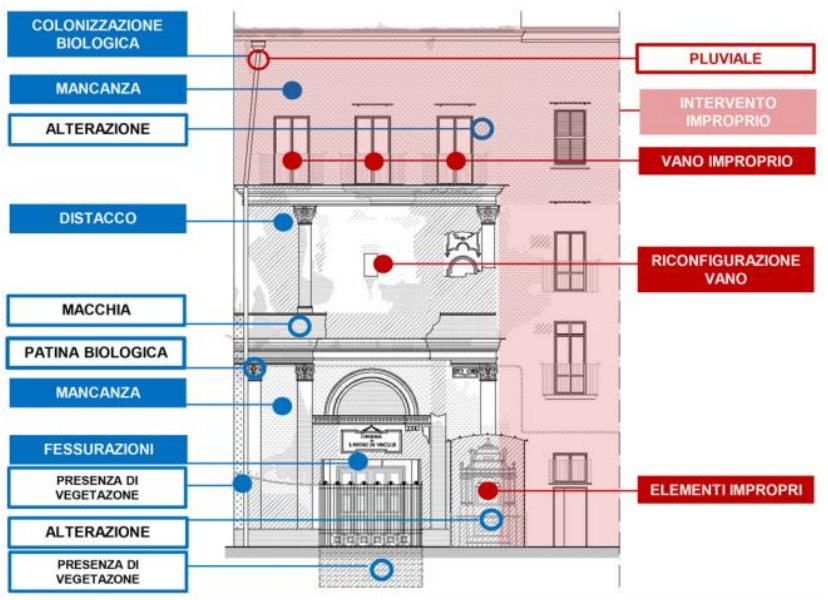

Figure 3. Facade of Church of San Pietro in Vinculis, decay mapping.

This paper reports the results of these experimentations, in relation to a case study located in the Church of San Pietro in Vinculis in Naples (fig. 1). The peculiar condition of decay, due to the abandonment of the church in the last decades, has made it possible to test the compliance of the digital tools set up, in relation to a wide range of phenomena (figg. 2,3)

\section{THEORETICAL BACKGROUND}

The diffusion of HBIM systems, hence the application of object oriented processes regarding the historical built heritage, have highlighted the need to individuate specific procedures for the modeling of elements and characteristics that traditional BIM systems do not allow, looking forward to replicate in the digital space not only the metric dimensions of the buildings, but also what concerns conservation state, hence structural instability and the characterization of the surfaces affected by decay pathologies, in order to organize opportune interventions on them (Alshawabkeh, 2020, Tomalini et al., 2020, Tsilimantou et al., 2020, Brumana et al., 2017, Lo Turco et al., 2017, Bruno et al., 2017, Vidovszky, 2016, Clini et al., 2014, Meschini et al., 2013). In fact, the possibility to structure infographic databases in $\mathrm{H}$ BIM systems holds a significant relevance for the purpose of conservation and valuation of the existing architectonical heritage (Campi et al., 2017; Scandurra et al., 2018).

Indeed, in its various forms, this latter constitutes a high-value record, as it expresses culture, history, languages of past epochs, characterized by its compositive and constructive peculiarities.

For the purpose of its knowledge and considering the progressive decay this heritage is subjected to over time, the need to perform accurate surveys and multidisciplinary analyses seems evident, in order to read and document the building in its complexity, taking into account, in addition to its metrical evaluations, also its conservation state and structural stability.

Currently, decay and crack patterns are documented through 2D dithering of plan views of the building. This is performed by visually recognizing the types of decays and tracing the contour lines of the respective areas in a traditional way, through painting tools, in CAD drawing. The main limit of these approaches consists in the fact that complex details cannot always be efficiently modelled, and then represented, in easily recognizable geometric shapes (Poux et al., 2016). The most advanced approaches in the research of a fast solution for the representation of decay areas use the chromatic information a 2D picture for data segmentation (Meschini et al., 2013, Tomalini et al., 2020, Lo Turco et al., 2020). Moreover, simple imaging techniques allow the individuation and the extraction (vectorization) of area borders from basic RGB images, as long as they are defined and recognizable (Alshawabkeh, 2020). Despite being vectorized and measurable, plan views do not allow to relate a documented decay pathology and its continuations on orthogonal surfaces, to what is present in the view, leading to a simplification in the evaluation of quantities and to a gap in the data. Moreover, in non-BIM software decay areas are not mutually relatable: they appear as amorphous, meaningless, non-queryable areas, unaware of the relationships between the real phenomenon, its adjacent occurrences, and the surface it affects. In BIM environments, as of today, there are no applications for this specific aspect that characterizes the built architectonical heritage. So, there is still a difficulty concerning times and procedures with which, through escamotages and stretches, object oriented parametric modeling can be brought closer to deliver this type of information as well (di Luggo et al., 2017). The present study proposes a possible solution for the documentation of decay and crack pattern.

\section{HBIM TOOLS}

\subsection{Decay area}

In order to define the operational structure of the digital tool destined to decay mapping on the 3D model and its general approach toward documentation in a digital environment, the definitions contained in UNI11182 code were one of the main references. As it is well-known, the code lists all the possible typologies of phenomena for the surfaces of an architectonical 


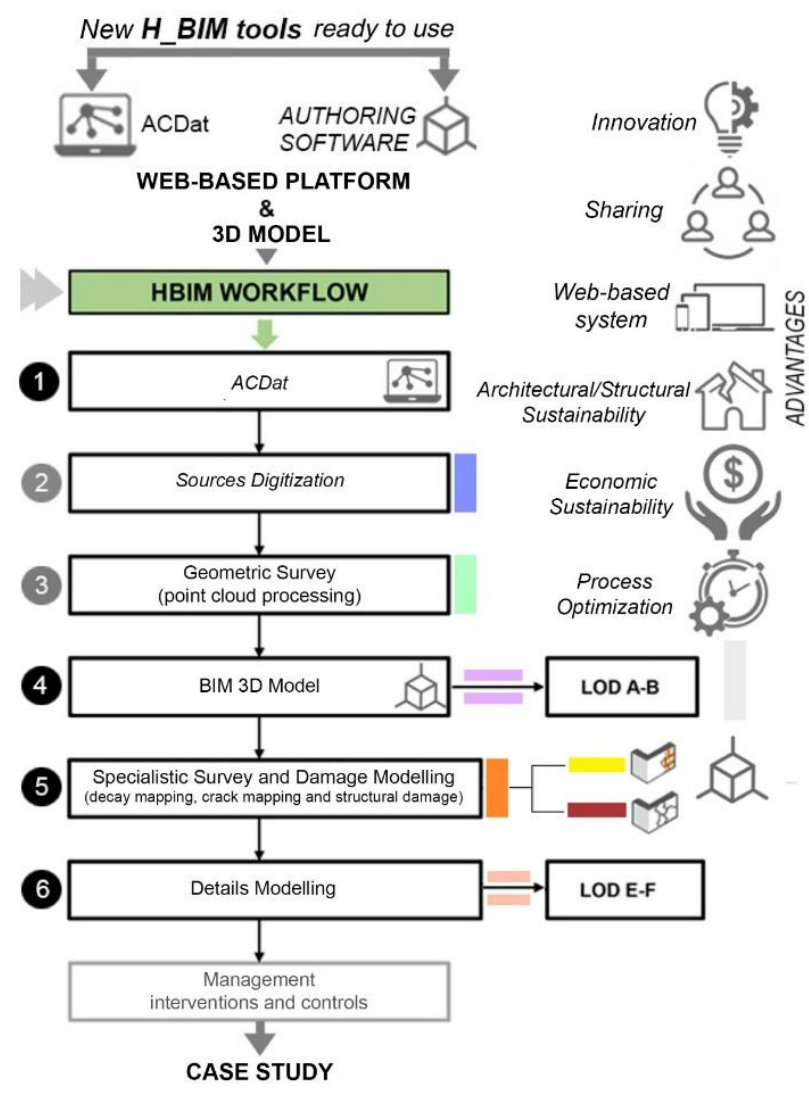

Figure 4. H-BIM workflow: steps and tools.

construction, differing alteration phenomena from degradation phenomena. While alteration refers to the modification of $a$ material that does not necessarily imply a deterioration of its characteristics of conservation, the term degradation refers to the modification of a material that entails a worsening of its characteristics in terms of conservation.

In this experimentation, even though the new H-BIM object was generically named decay area, it has been considered fundamental to keep trace of its specific characterization in the functionalities of the digital tool, to ease data query after its complete modeling. For the same reason, it has also been chosen to further subdivide the degradation category into additive phenomena and subtractive phenomena, to simplify the structure of the related information tools and to identify them immediately. In operational terms, the new H-BIM object has been imagined as a brush with variable width. The contour and the extension of the brushing area can be freely defined by the user, without hinges of predefined shapes nor in the number of vertexes/sides, so that the most suitable level of detail can always be attained. The surfaces of the digital model are then colored by the decay phenomenon that is being reported. The parameters that characterize the decay area object are multiple. The geometric ones affect area, width (additive phenomena) and depth (subtractive phenomena); the graphical ones involve the customization of pattern and color to represent the specific phenomenon at best; the informative ones report the descriptions provided by the code, if applicable, the description of survey or intervention operations, as they are indicated in restoration textbooks (Torsello et al., 2003, La Regina, 2009, Franceschi et al., 2010); the possibility to add freely customizable notes. It is also possible to choose, according to the cases, if non-adjacent areas of the same typology should be queried as a group or singularly. All the described operations take place directly in a tridimensional space, so that the operator is not subjected to default projection planes and can map graphic information by rotating, moving and zooming the model in the most opportune way.

This research has been developed through a collaboration between structural engineers and researchers with expertise in the fields of survey and representation, looking forward to pursuing a deeply shared work structure. So, the realization of the digital tools was driven by the purpose of answering needs of various kinds: knowledge systematization, metric survey and compositional analysis, structural assessment, analysis of the state of conservation (fig. 4).

\subsection{Crack}

Concerning the documentation of the historical heritage, reporting the crack pattern results to be fundamental and the approach for their representation is analogous to that of decay areas, that is the use of an additional tool designed and realized to enhance the H-BIM toolbar of the Edificius software.

The tool has been dubbed crack and allows, by proceeding with painting-based modeling, to reproduce on the digital model the crack distribution surveyed on the real building.

Following a discretization of the characteristics of the phenomenon according to the decay area, the crack tool does not require to define a closed polygon but, rather, lines.

The width, as in real conditions, can be variable, and hence can correspond perfectly to the specific features of the surveyed phenomenon. After reproducing its shape, the characterization of the specific crack occurs through the customization of the values of the various parameters chosen in this research. In fact, these latter have been chosen to be typology (isolated, cross-shaped, diffuse), entity (defined as a function of the maximum crack width), causes, displacement, position of the central point, graphical aspect, description. It is also possible to specific if the crack is passing or not passing, and if it caused a material loss.

\subsection{Ortophoto, symbolic representations and legenda}

In order to facilitate painting operations, as part of the reflections arisen from the research, it was decided to include in the H-BIM toolbar a tool (Orthophoto) that allows the user to project the rectified images derived from the $3 \mathrm{D}$ survey on the surfaces of the model. In this way, by adapting and positioning the orthophotos derived from the point clouds, it is possible to use a photorealistic graphic support for the digitization of surface degradation phenomena and cracks.

Considering the wide presence of decay phenomena on the surfaces of historical buildings and the small size of many cracks in relation to the dimension of the whole building, it was considered necessary to reflect on the level of graphic detail that the smart objects decay area and crack should have at each view scale.

Five possible advancements in the scale of representation of the phenomena have been set, starting from a symbolic 


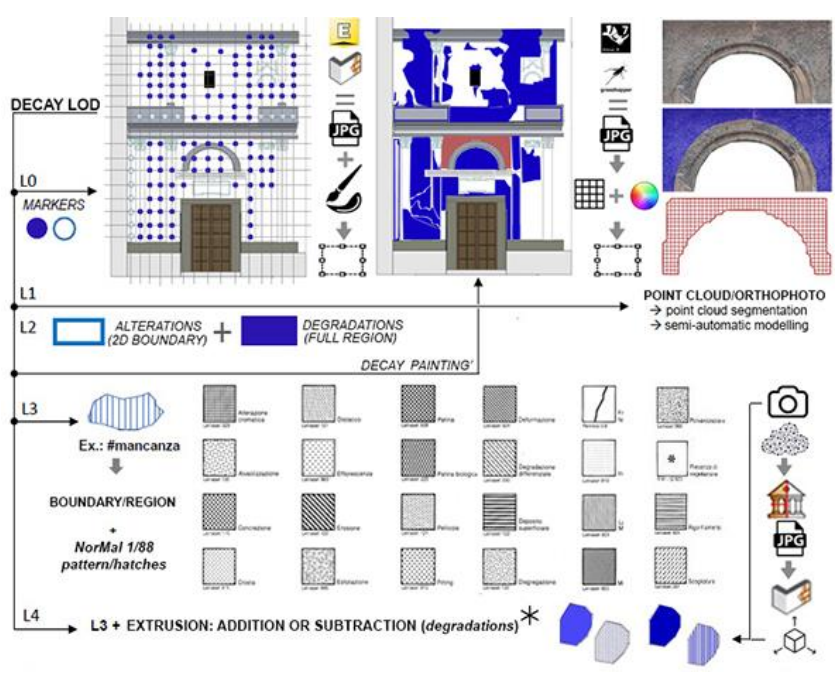

Figure 5. Five level of detail in decay representation: L0 L1, L2, L3, L4 between iconic and reality-based representation.

representation up to one that realistically reproduces the phenomenon. This solution is compatible with a LOIN-oriented approach, as it allows to implement the model through the graphical modalities considered more suitable to the LOD of the model itself, according to the specific in-depth phase of the digitalization process. In the realization of the software application, this need has been turned into the preparation of symbols that can be automatically added to decay areas and cracks, to be inserted by a check in the table of attributes of the smart object. These, like labels, allow a fast individuation of the analyzed theme also in the following phases of consultation of model consultation.

On the whole, the H-BIM tools decay area and crack have therefore allowed to reach the 3D modeling and the symbolic labeling of the corresponding phenomena.

Also exploiting the automatisms of the BIM environment has allowed the automatic and updatable creation of tables and legends of the mappings individuated on the model, adopting for them the pattern and the descriptions inferred from the NorMaL - 1/88 lexicon (fig. 5).

\section{EXPERIMENTAL CASE}

\subsection{Data acquisition}

The tools realized for the H-BIM toolbar of Edificius have been used to model the material decay and the crack pattern of the case study chosen to test the beta version of the software.

For the Church of San Pietro in Vinculis, the first part of the work focused on the investigation of the historical, graphic and textual sources, in order to clarify the constructive specificities and the transformations that brought the organism to the current conformation.

The church, dating back to the XV century, has undergone several renovations and modifications over time. Among the most important ones, expansions are documented in the XVI century and restorations in the XVII century (Divenuto, 1990). From the compositional point of view, it presents a single aisle covered by a barrel vault with lunettes, with three chapels on each side, marked by pilasters of composite order. For the metric survey, it was decided to use 3D acquisition techniques, integrating different types of instruments to optimize the specificity of the results.

In the first survey campaign, a Faro Focus 3D s120 laser scanner was used, which made possible the acquisition of a sufficiently detailed and accurate metric data, despite the poor lighting of the interior. Point cloud processing took place in the proprietary software Faro Scene, which produced an overall point cloud in gray scale. The resolution and then the densification of the points chosen in the acquisition phase allowed a clear reading of the variations in the texture of the surfaces and a clear identification of the cracks in the interior and on the exterior. Subsequently, color data were integrated through surveys carried out with the aid of an ultralight Parrot drone, using generators and batterypowered spotlights to improve the internal lighting condition. Following consolidated practices, the acquired photos have been processed in the SfM Agisoft Metashape application to build a different point cloud from them. Starting from this, the different photos have been univocally arranged in the digital space in order to texturize the overall survey data.

The combination of the results of the two survey campaigns has in fact allowed to obtain 3D metrically accurate and photorealistic data. Considering the type of objective that was intended to be achieved in the specific testing phase of H-BIM tools made with ACCA software, a series of orthophotos were preliminarily produced from the point cloud, to be used later as a visual support for the pathologies and for the phenomena to be subjected to in-depth investigation, i.e. decay areas and cracks.

\subsection{Data modelling}

During data output phase, the workflow included an initial operation of simplified architectural modeling of the architectural organism, aimed to the preparation of a container immediately consultable also during the following inspections, destined to the specific understanding of the state of degradation of the surfaces directly on the field.

Then, the architectural-structural modeling has been detailed in order to expedite the recognizability of the components of the church and to localize better the parametric objects developed for the documentation of the crack pattern and of the decay pathologies of the surfaces. Therefore, a BIM simulation model of the metric and geometric characteristics of the church has been realized, using the point clouds from the $3 \mathrm{D}$ surveys as starting data. The phase of identification of the semantic identity of each object and of the respective relations has allowed a higher level of categorization of the parts of the building, defining their grouping in macro and micro elements, identified on the basis of the architectural typology that is being analyzed. This deeper level of clustering has been referred to the decomposition of the Church in functional elements (aisle, facade, chapel, etc.), thus facilitating the reading of data related to decay and to the crack pattern. In fact, it was considered that the attribution of a given decay phenomenon to a specific area of the building could ease the following evaluation of the possible causes and, therefore, the design of interventions.

During the testing phase of H-BIM tools, it was decided to focus decay and crack mapping on the main façade and on the two 


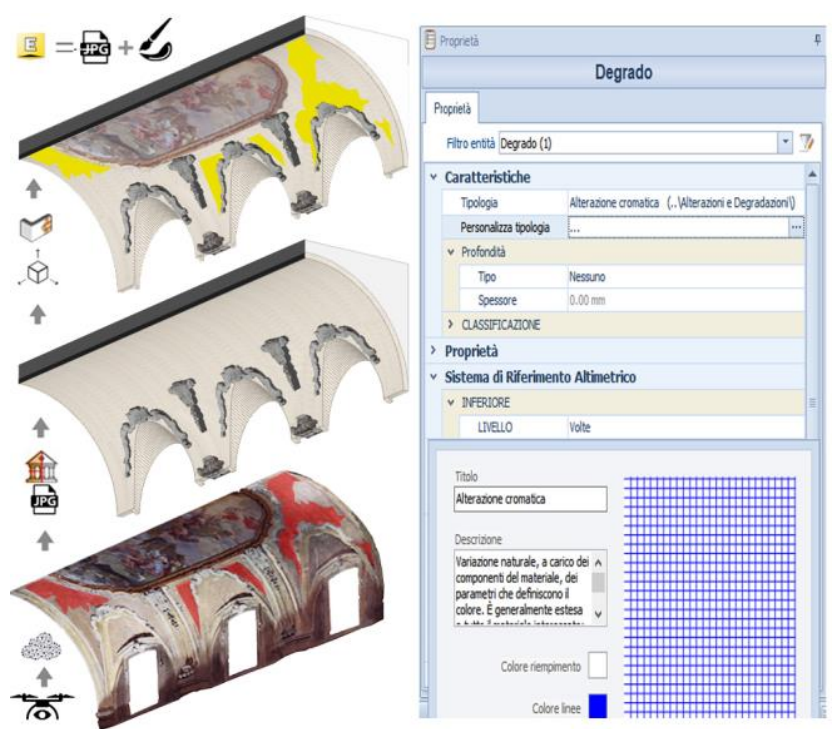

Figure 6. Parametric H-BIM objects: decay mapping of vaults.

internal longitudinal sections, verifying the applicability and the limits on several types of modeled surfaces.

After processing survey data, orthophotos were used for the identification of the various pathologies, projecting them on the surfaces as if they were material patterns. Orthophoto editing was conceived so that, despite projecting a single view of the point cloud only on one plane (the plane of the image) they could be adapted to the surface of the model, that is to surface portions that in $3 \mathrm{D}$ views are arranged on planes at different depths.

For the main façade, adopting the specific terminology that indicates the types of degradations and alterations reported in the mentioned UNI11182 code, many phenomena of material decay have been identified (chromatic alteration, dust, detachment, stain, loss, biological crust, presence of vegetation), numerous cracks, as well as evident modifications in the original form of the façade, revealed by the presence of improper elements and systems of different nature.

For each of the typologies found, painting and characterization phases were performed.

The current version of the tool effectively meets the expectations in terms of time reduction and informative implementation, even for complex surfaces, that is those for which identifying planes is difficult. Surfaces with curvilinear direction, for example, are discretized into a series of small faces to correctly perform mapping. This kind of scenario occurred when mapping the surface conditions of vaults and molded stuccoes, elements that are known to be very present in the historical architectonical heritage and that, therefore, cannot be overlooked by tools created for H-BIM (fig. 6).

It was therefore possible to further develop this integrated process following the results of the experiments recently conducted for the informative modeling of the vaulted surfaces (Lanzara et al., 2021), which allowed to identify appropriate parametric objects to properly document the historical built heritage in H-BIM systems.

In order to allow the reading of the information concerning decay and crack patterns also when extrapolating traditional 2D plan views, a symbolic visualization of the data has been realized in the form of labels displaced in correspondence of the surface intercepted by the cut plan.

While the management of the labels has been made customizable, the symbology has been fixed in the research project so that it would be univocally recognizable.

\subsection{Data implementation}

While experimenting the tools provided by ACCA software, another topic of research has been the implementation of the data that can be subjected to input in the collaborative platform usBIMplatform, again in relation to decay and crack patterns.

The CDE (Common Data Environment) structure in the platform is based on the aspects previously described with reference to the proposed Scan-to-BIM workflow.

In particular, the activities of Geometric Survey, BIM Modeling, Decay and Crack Pattern Survey and Modeling have been structured according to it.

As for all the other aspects, parameters related to the material decay of the surface and to the crack pattern have been systematized into the organization of specific descriptive sheets to be attributed to the macro-elements or to the single elements composing the model (fig. 7).

Specifically, the sheet concerning decay has been conceived so that it could be used by the operator since the first on-site inspection, that is, it provides a series of fields whose entries

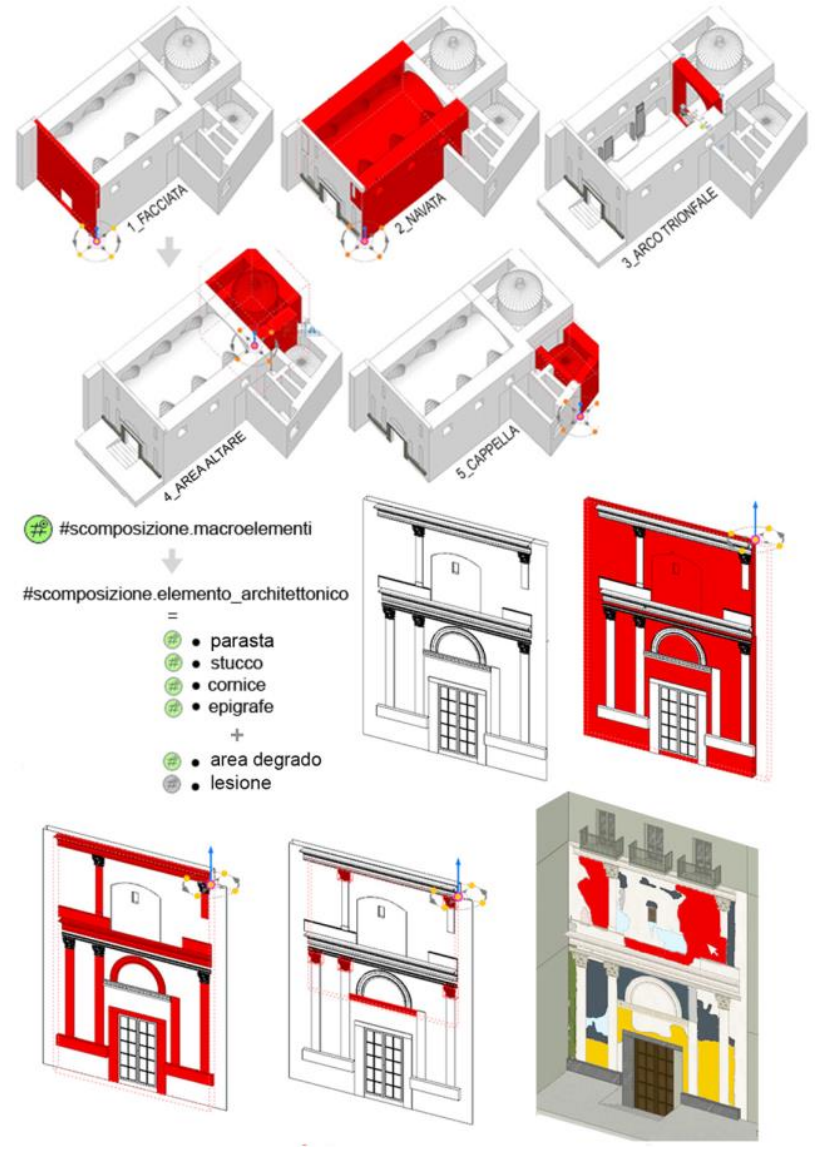

Figure 7. Semantic decomposition of architectural complex system: from macro-elements to micro-elements. 


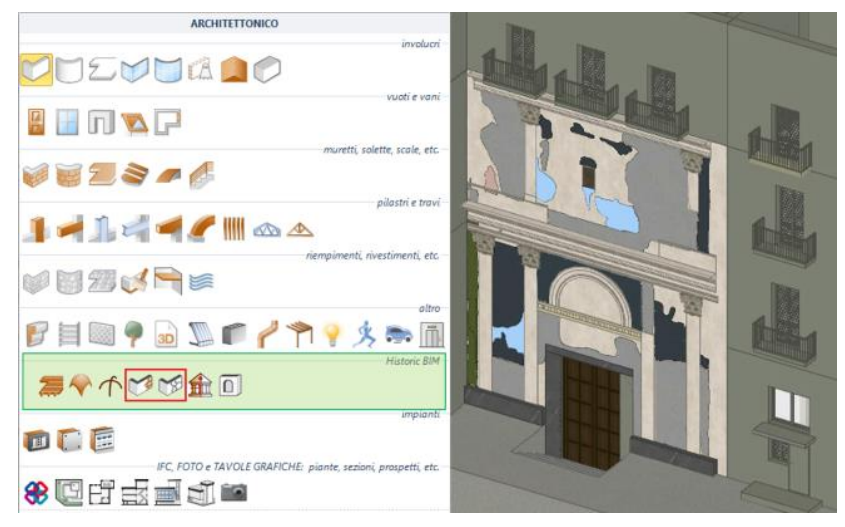

Figure 8. The Heritage BIM Toolbar (Edificius - ACCA software).

allow the systematization of the information collected in each phase of the documentary process.

In the first part, the sheet layout provides the possibility to insert one or more photos of the phenomenon, notes on its displacement and reference eidotypes.

Then, a sequence of sliders and checkboxes express the descriptive parameters of the phenomenon from a geometric, chemical and physical point of view, as well as the possible causes. Finally, a slot allows the insertion of general notes. The sheets have been divided into multiple and specific.

While multiple sheets can be attributed to large portions of the model (macro element) and can contain the description of all the phenomena detected, these latter are specific for each typology of decay and, therefore, each one can be attributed to a single modeled area (fig. 9).

Thanks to the possibility of loading on the platform point clouds, models and sheets, in fact, information can be correlated at best, facilitating the phases of query and analysis. The platform includes, in fact, a series of functions to identify (\#tag), to document (link) and to localize (marker) the elements (macro and micro) that characterize a model and the related information storage. In this regard, the subdivision of the model of the Church of San Pietro in Vinculis in macro elements has turned out to be particularly suitable: according to this approach, each of them has been turned into a container of information categories with greater detail, defined by a specific functional hierarchy.

After the survey, BIM modeling and the architectural characterization of the pathologies and damages that affect the buildings, the possibility of using the final model for an assessment of the seismic vulnerability of the church was tested. This process necessarily requires a simplification when applied to historical buildings since there are objective difficulties in defining verification procedures of safety requirements like those applied to ordinary buildings, given their typological variety and constructive singularity.

Existing evaluation tools are based on a scrupulous collection of information supported by special pre-compiled sheets and on the verification of structural behavior in an experiential form. In such a way it comes to a formulation of a preliminary qualitative judgment in reference to the seismic risk.

The Ministry for Cultural Heritage and Activities and Tourism (MIBAC) has issued the Guidelines for the evaluation and reduction of seismic risk of cultural heritage aligned to the new

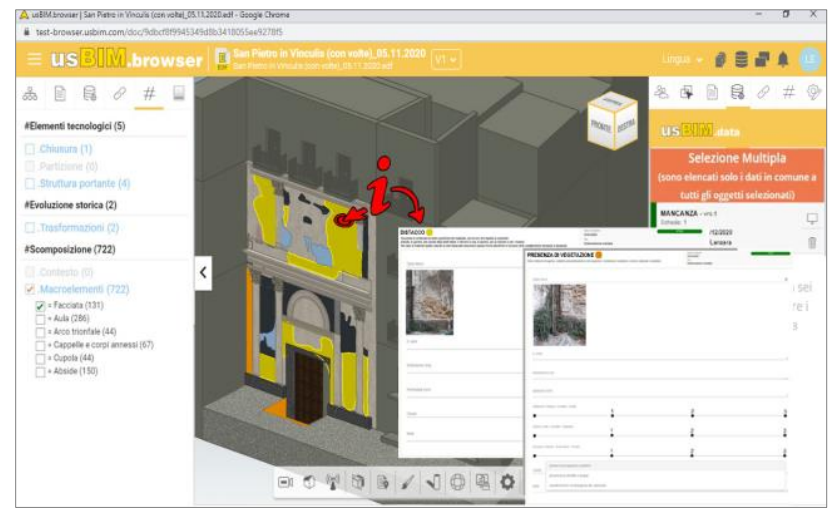

Figure 9. Data implementation: informative sheets (web-based CDE).

Technical Standards for Construction (D.M. 14-01-2008), in which it has identified 3 distinct levels of seismic vulnerability assessment. In the case of the Church of San Pietro in Vinculis the considered level was LV1, which allows to characterize seismic action at SLV (Stato Limite di salvaguardia della Vita, Life Safety Limit State) through simplified methods, based on a limited number of geometric parameters and using qualitative data (visual inspection, analysis of construction features, etc..), or the data collected during the investigations according to filing and tools provided by ACCA software.

In most of the churches it is scarcely significant to assume a unitary and overall behavior so portions of the structure having a behavior similar to the monolithic one, called macro-elements, are set as a reference and analyzed through a simplified model based on the following parameters:

- peak ground acceleration corresponding to the various limit states,

- vulnerability index iv, obtained through an appropriate assessment of the elements concerning vulnerability and anti-seismic protection.

The adopted methodology considers 28 possible damage mechanisms for the macro-elements of the church.

For each mechanism, an additional sheet, among those available on the platform, was created and in each of them the possible elements of anti-seismic protection and vulnerability indicators are suggested.

The sheet shows the indication of the anti-seismic devices that can contrast the activation of each kinematic mechanism and a number of vulnerability indicators, which measure propensity to damage (fig. 10).

Each of them is associated to a judgment on the effectiveness modulated on three levels (0: ineffective; 1: fair; 2: good; 3 : completely effective).

The last box reports damage assessment, which must be carried out in accordance with the 5 damage degrees suggested by EMS98 methodology. A distinction is also made between the current damage, corresponding to that observed at the time of the inspection, and the progressive damage, which is related to phenomena occurred before the seismic event under investigation. Thanks to a law of direct correlation between the seismic input associated to the different limit states and the detected vulnerability based on a statistical analysis of previous seismic experiences and provided by the abovementioned guidelines, the values of peak ground acceleration, corresponding to the Damage Limit State (SLD, Stato Limite di Danno) and to 


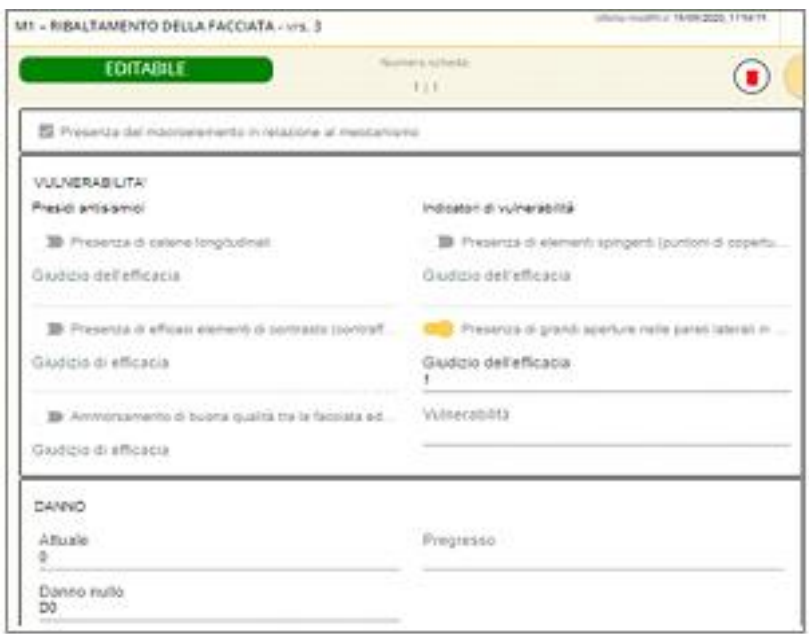

Figure 10. Structural information: on-line fillable data sheets.

the Life Safety Limit State (SLV) have been calculated through the following equations:

$$
\begin{gathered}
a_{S L D} S=0.0025 \times 1.8^{2.75-3.44 i_{v}} \\
a_{S L V} S=0.0025 \times 1.8^{5.1-3.44 i_{v}}
\end{gathered}
$$

Hence, it is possible to define an acceleration factor as the ratio between the acceleration that brings the building to SLV and the expected acceleration on the site corresponding to the reference return period, both referred to the soil condition A:

$$
f_{a, S L V}=\frac{a_{S L V}}{a_{g, S L V}}
$$

The illustrated procedure, despite following established practices, has been implemented and facilitated using the digital tools realized for the usBIMplatform and the H-BIM toolbar, which have significantly simplified its application. Thanks to usBIM.data application, in fact, each of the elements composing the macro-element of the church was assigned sheets regarding decay, cracks and corresponding mechanisms, deeply expediting the comprehension and analysis of the current state.

For the evaluation of the parameters, to be performed in further developments, an additional common sheet has been realized for all the mechanisms.

\begin{tabular}{|c|c|c|c|c|c|}
\hline $\begin{array}{c}\text { DAMAGE } \\
\text { INDEX (ID) }\end{array}$ & $\begin{array}{c}\text { VULNERABILITY } \\
\text { INDEX (Iv) }\end{array}$ & $\begin{array}{c}\mathbf{a}_{\text {SLV }} \\
(\mathrm{g})\end{array}$ & $\begin{array}{c}\mathbf{a}_{\text {SLD }} \\
(\mathrm{g})\end{array}$ & $\begin{array}{c}\mathbf{a}_{\mathrm{g}, \mathrm{SLV}} \\
(\mathrm{g})\end{array}$ & $\mathbf{f}_{\mathbf{a}}$ \\
\hline 0.21 & 0.5 & $\mathbf{0 . 1 8}$ & $\mathbf{0 . 0 5}$ & $\mathbf{0 . 2 6}$ & $\mathbf{0 . 7 0}$ \\
\hline
\end{tabular}

\section{CONCLUSIONS AND FUTURE DEVELOPMENTS}

The research activities carried out are the first step of a work in progress aimed at the algorithmic-generative (semi-automatic) representation/modeling of degradation areas within processes that, starting from reality-based surveys, lead to the informative modeling of an existing building. The objective of the project was to allow decay phenomena the mapping and typization in H-BIM systems with the possibility of obtaining photorealistic rendering of the model, representation of decay areas and automatic legenda generation, but above all a viewable H-BIM model that can be implemented and updated over time in line with the

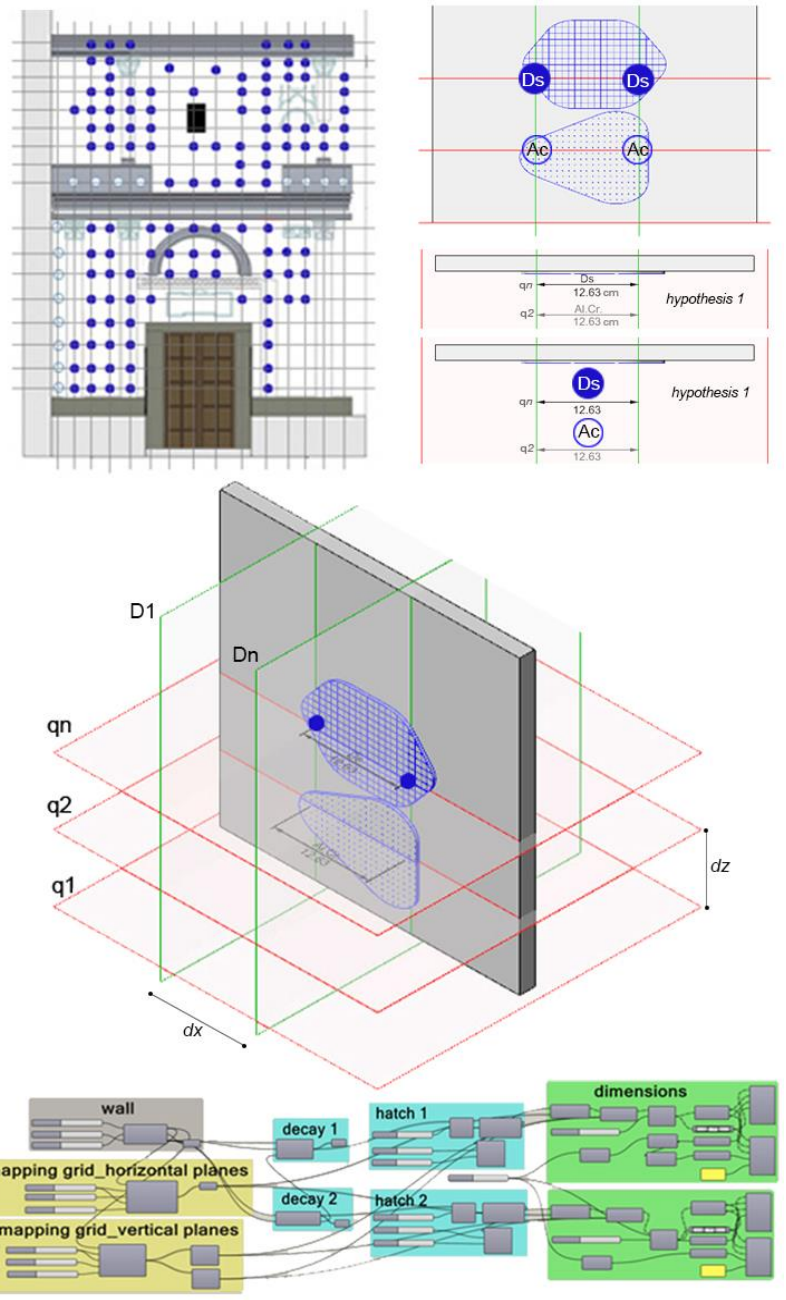

Figure 11. Semi-automatic - parametric decay representation (VPL): planimetric graph.

following management and maintenance interventions and phases of the building. Further developments of the project include the creation of 2D alternative thematic drawings with the possibility to report in a planimetric graph, obtaining in this way, when consulting a single level of the building, not only decay areas directly intercepted by the section plan, but also the areas overlapped and comprised between the section plan and the plan of the level under analysis.

On the basis of these premises, the work in progress research activities are aimed at the algorithmic-generative (semiautomatic) representation/modeling of the decay areas reported in the orthophotos processed from the point clouds (fig. 11). The final objective remains the reduction of the time required for the output of significant data in H-BIM models.

\section{REFERENCES}

Alshawabkeh, Y., 2020. Linear feature extraction from point cloud using color information. Heritage Science (2020), 8:28.

Bruno, N., Roncella, R., 2017. Il BIM per gli edifici storici, potenzialità e criticità. Il caso del Duomo di Parma.

Brumana, R., Della Torre, S., Oreni, D., Previtali, M., Cantini L., Barazzetti, L., Franchi A., Banfi, F., 2017. HBIM challenge among the paradigm of Complexity, tools and preservation: the 
Basilica di Collemaggio 8 years after the earthquake (l'Aquila). In ISPRS. Int. Arch. Photogramm. Remote sens. Spatial inf. Sci., Vol. XLII-2/W5, pp. 97-104.

Campi, M., di Luggo, A., Scandurra, S., 2017. 3D modeling for the knowledge of architectural heritage and virtual reconstruction of its historical memory, in Int. Arch. Photogramm. Remote Sens. Spatial Inf. Sci., vol. XLII-2/W3, pp. 133-139, https://doi.org/10.5194/isprs-archives-XLII-2-W3-133-2017, 2017.

Clini, P, Quattrini, R., 2014. Colore, riflettanza e temperatura. Dal caso studio di Villa Trissino a nuove applicazioni integrate di dati lidar terrestri per il rilievo e la diagnostica. Color Culture and Science, 02/14.

di Luggo, A., Pulcrano, M., Scandurra, S., Tarantino, C., 2017. Modellazione H-BIM e ricostruzione delle trasformazioni del costruito storico, in 3D Modeling \& BIM progettazione, design, proposte per la ricostruzione, pp. 178-195. Dei Editore.

Divenuto, F. 1990. Napoli Sacra del XVI secolo. Edizioni Scientifiche Italiane.

Franceschi, S., Germani, L., 2010. Manuale Operativo per il Restauro Architettonico. Metodologie di intervento per il restauro e la conservazione del patrimonio storico. Dei. Tipografica del Genio Civile.

La Regina, F., 2009. Il restauro dell'architettura, l'architettura del restauro. Napoli: Liguori Editore.

Lagormarsino, S., Podestà, A., 2005. Inventario e Vulnerabilità del Patrimonio Monumentale dei Parchi dell'Italia CentroMeridionale. Vol. III. Analisi di Vulnerabilità e Rischi degli Edifici Monumentali. L'Aquila: INGV/GNDT - Istituto Nazionale di Geofisica e Vulcanologia/Gruppo Nazionale per la Difesa dai Terremoti.

Lanzara, E., Scandurra, S., Musella, C., Pulcrano, M., Palomba, D., Asprone, D. and di Luggo, A., 2021. Parametric Modelling of vaults and shared implementation of the data in HBIM system. In Proceedings of 3DMODELING\&BIM WORKSHOP. Digital Twin. Roma, April 14, 2021.

Lo Turco, M., Calvano, M., Giovannini, E. C. and Tomalini, A. 2020. AIM! Algorithmic Information Modeling: New Strategies for a Fully Integrated Approach in the Field of Cultural Heritage. In Bolognesi, Cecilia, Villa, Daniele (Eds.), From Building Information Modelling to Mixed Reality. Springer, Cham.

Lo Turco, M., Mattone, M. and Rinaudo, F. 2017. Metric survey and bim technologies to record decay conditions. In The International Archives of the Photogrammetry, Remote Sensing and Spatial Information Sciences, Volume XLII-5/W1, 2017. GEOMATICS \& RESTORATION - Conservation of Cultural Heritage in the Digital Era, 22-24 May 2017, Florence, Italy.

Meschini, A., Pelliccio, A., 2013. Il colore nel rilievo strumentale: laser scanner, termografia e postprocessing dei dati in un sistema GIS.
Napolitano R, Hess M, and Glisic B., 2019. Integrating nondestructive testing, laser scanning, and numerical modeling for damage assessment: the room of the elements. Heritage. 2019;2(1):151-68

Poux F, Hallot P, Neuville R, Billen R. Smart point cloud: defnition and remaining challenges. ISPRS Ann Photogramm Remote Sens Spat Inf Sci. 2016;4(21):119-27.

Scandurra, S., Pulcrano, M., Cirillo, V., Campi, M., di Luggo, A., Zerlenga O., 2018. Integrated survey procedures for the virtual reading and fruition of historical buildings, in Int. Arch. Photogramm. Remote Sens. Spatial Inf. Sci., vol. XLII-2, pp. 1037-1044, https://doi.org/10.5194/isprs-archives-XLII-2-10372018, 2018.

Tomalini A., Giovannini, E. C., 2020. An algorithmic information model (AIM) for the map of decay: the church of San Giuliano. In Dienne, Vol. 7, 2020, pp.130-140.

Torsello, B. P., Musso, S. F., 2003. Tecniche di restauro architettonico. In Trattato di restauro architettonico (collana). Torino: Utet.

Tsilimantou, E., Delegou, E., T., Nikitakos, I. A., Ioannidis, C. and Moropoulou, A. 2020. GIS and BIM as Integrated Digital Environments for Modeling and Monitoring of Historic Buildings. In Applied Sciences 2020, 10, 1078.

Vidovszky, I. 2016. Impact-based diagnostic approach for maintenance monitoring of historic buildings. In Procedia Engineering, 164 (2016), pp. 575 - 582. 